\title{
A Study on Guide Sign Validity in Driving Simulator
}

\author{
Wei Zhonghua \\ Transportation Research Center, Beijing University of Technology, No. 100, Pingleyuan, Chaoyang District \\ Beijing, China \\ E-mail: weizhonghua@bjut.edu.cn \\ Chen Xuemei ${ }^{1}$ \\ School of mechanical and vehicle, Beijing Institute of Technology, No. 5, Nan Da St, Zhongguancun, Haidian District, \\ Beijing, China \\ E-mail:chenxue781@126.com \\ Gong Ming \\ Transportation Research Center, Beijing University of Technology, No. 100, Pingleyuan, Chaoyang District \\ Beijing, China \\ E-mail: gongming@emails.bjut.edu.cn \\ Received 3 August 2011 \\ Accepted 25 November 2011
}

\begin{abstract}
The role of guide sign to inform road user about the information of network is important. How to design and locate guide sign to increase traffic operation efficiency is a key point for traffic engineers. Driving simulator is useful devised to study guide sign in the process and system control. For the purpose of studying guide signs using the tool of driving simulator, guide sign's validity in driving simulator was studied. Results of this experiment are the foundation of further study on guide sign. Simulator calibration procedure for guide sign was set up in this study. Legibility distance as measure of performance was used to evaluate the validity of guide sign in driving simulator. Thirty two participants were recruited. Results indicated legibility distance and speed were inversely related with the method of data mining. Legibility distance and text height of guide sign were positive related. When speed is $20 \mathrm{~km} / \mathrm{h}, 30 \mathrm{~km} / \mathrm{h}, 40 \mathrm{~km} / \mathrm{h}$, magnifying power of text height is $4.3,4.1,3.8$, while guide signs are absolute validity in driving simulator.
\end{abstract}

Keywords: Driving simulator; guide sign, validation; Process and system control; Data mining.

\section{Introduction}

\subsection{Study in Simulator}

With the remarkable development of electronic and computer technology, simulator technologies are being rapidly enhanced. Driving simulators have many merits such as simplified factors, easy-to-detection data, safety, repeatability and cost-effective. At present, studies conducted in driving simulator mainly focus on road safety treatments evaluation ${ }^{[1]}$, variable message sign ${ }^{[2]}$, driver's capability ${ }^{[3]}$, road landscape design ${ }^{[4]}$, and so on. Driving simulators have become an increasingly widespread tool to study problem in transportation area.

\subsection{Validation of Driving Simulator}

With the continuous application of driving simulator in study, researchers have started to focus on simulator validation to ensure data measured in driving simulator

${ }^{1}$ Chen Xuemei is the corresponding author. 
was validity and accuracy. Blaauw proposed two types of driving behavioral validity: absolute validity and relative validity[5]. Absolute validity is that the numerical values between the two systems are the same. Relative validity is that differences found between experimental conditions are in the same direction, and have a similar or identical magnitude on both systems. Many previous studies on driving behavior validation in driving simulator have evaluated driving simulator's validity based on driving behavior performance. Kaptein found that route choice behavior is generally absolute validity, speed and lateral control behavior is relative validity by comparing field and simulator study results[6]. Klee conducted a study to evaluate if the fixbase driving simulator could provide a realistic driving experience[7]. The results indicated that the drivers behaved similarly at 10 of 16 designated locations along the road, but the difference in mean speeds between the simulator and the field indicated a tendency of drivers to travel at slower speeds in the simulator. Bella conducted a simulator speed validation study on work zone[8]. Speed measurements were conducted for both field observations and driving simulator tests in the transition area, the activity area, the termination area, and the advance warning area. The results indicated that differences between the speeds observed in the real situation and those measured with the simulator were not statistically significant, which demonstrated driving simulator in absolute terms. Yan investigated if the driving simulator can be used as a valid tool to assess traffic safety at signalized intersections[9]. The difference in surrogate safety measures between the simulator and the field validated the driving simulator in relative terms.

\subsection{Signage Study in Simulator}

Traffic sign as an important device traffic management system can improve traffic operation efficiency and safety. The study on traffic sign in driving simulator was rare especially guide sign. Dutta conducted study to the joint effect on driver performance of: obstructions of variable message signs[2]. The sequence of a two phase message, the message content, the number and direction of lane changes required by the driver based on the message presented. Two types of message duration were considered. Results indicated when a message was presented for a relatively short duration and repeated twice during the time in which it was visible and led to a good driver performance. However, the validity of VMS (Variable Message Signs) in driving simulator was not considered. Ting's studied visual differences leading to differences in the legibility distances of traffic signs between driving simulators and real road environments[10]. Results showed that the proposed theoretical equation for predicting legibility distance and the simple algorithm for determining the magnifying power of traffic signs reduced the difference in legibility distances between the simulator and real road environment under quasi-static and dynamic driving conditions.

According to the literature review, there is no validation study focusing on guide sign. This study aims at investigating the guide sign's validity in driving simulator. It is the foundation of further study on guide sign to make sure the results' validity and accuracy in driving simulator.

This article assumes that guide sign induces a similar driving behavior in driving simulator and field. Namely guide sign was relative validity in driving simulator. Based on this hypothesis, legibility distances were measured corresponding to guide sign with different magnifying power. Regression models were set up to calculate reasonable magnifying power. And then, guide sign in driving simulator was absolute validity.

\section{Methodology}

\subsection{Simulator calibration procedure}

The simulation capability of visual system in different simulators varied even in the same simulator at different times. And the validity of traffic sign in simulator was sensitive to projector performance and configuration. For this reason, simulator calibration of visual system was needed at the beginning of project study, especially signs related research conducted in driving simulator.

A brief description of the procedure is provided in this section. The procedure is also depicted in a flow chart (Fig.1).

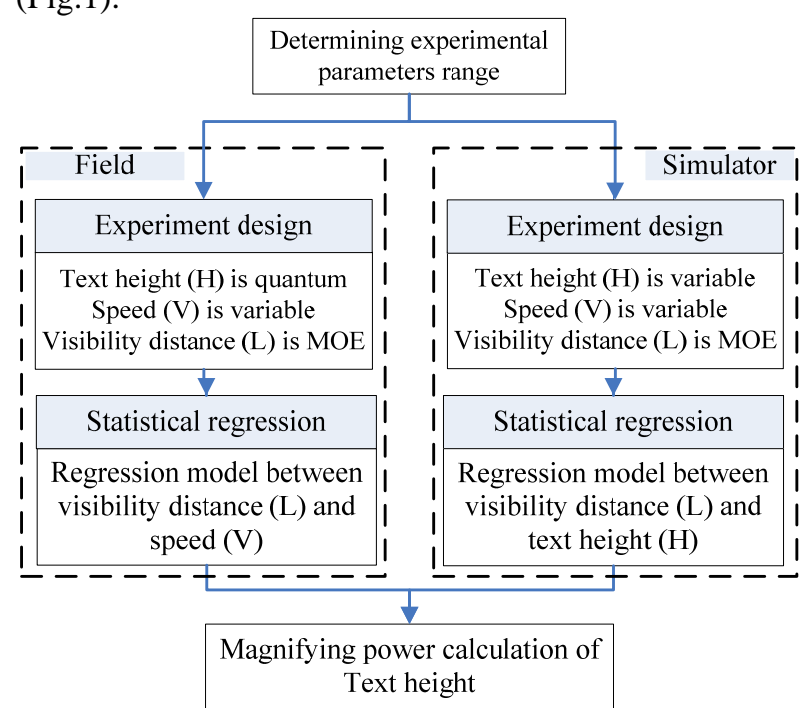

Fig.1. Simulator calibration procedure 
In the first step, the range of experimental parameters, including road grade, design speed and text height are determined. According to GB5768-2009[10] regulations, guide sign letter height and background color of guiding sign, respectively, was determined by the design speed and road level. Determining experimental parameters range can reduce impact factors and complexity in experiment.

This step implements experimental design for two scenarios field and simulator. In field experiment, text height is constant value, and legibility distance of traffic signs (dependent variable) is measured in different vehicle speed (independent variable). In simulator experiment, text height and vehicle speed are independent variables, and legibility distance is dependent variable.

Regression model was set up to find the relationship between factors. In field experiment, regression model (formula like Eq.1) was set up between vehicle speed $\left(\mathrm{V}_{\mathrm{f}}\right)$ and legibility distance $\left(\mathrm{L}_{\mathrm{f}}\right)$. In simulator experiment, Regression models (formula like Eq.2) were set up between text height $\left(\mathrm{H}_{\mathrm{s}}\right)$ and legibility distance $\left(\mathrm{L}_{\mathrm{s}}\right)$, and vehicle speed $\left(\mathrm{V}_{\mathrm{s}}\right)$ varied.

The last step of the proposed procedure is to calculate magnifying power. In specific speed condition, $30 \mathrm{~cm}$ text height corresponding to legibility distance in field is $\mathrm{L}_{\mathrm{f}}$. Supposing legibility distances in field and in simulator are equal, corresponding to the text height in simulator is $\mathrm{H}_{\mathrm{s}}$. $\mathrm{H}_{\mathrm{s}}$ can be calculated with Eq.3.

Finally, $\mathrm{H}_{\mathrm{s}}$ divided by $\mathrm{H}_{\mathrm{f}}$ equals $\mathrm{k}$ magnifying power (Eq.4).

$\mathrm{L}_{\mathrm{f}}=\mathrm{a}_{1} \mathrm{~V}_{\mathrm{f}}+\mathrm{b}_{1}$

$\mathrm{L}_{\mathrm{s}}=\mathrm{a}_{2} \mathrm{H}_{\mathrm{s}}+\mathrm{b}_{2}$

$\mathrm{H}_{\mathrm{s}}=\frac{1}{\mathrm{a}_{2}}\left(\mathrm{a}_{1} \mathrm{~V}_{\mathrm{f}}+\mathrm{b}_{1}-\mathrm{b}_{2}\right) \quad\left(\mathrm{V}_{\mathrm{f}}=\mathrm{V}_{\mathrm{s}}\right)$

$\mathrm{k}=\frac{\mathrm{a}_{1} \mathrm{~V}_{\mathrm{f}}+\mathrm{b}_{1}-\mathrm{b}_{2}}{\mathrm{a}_{2} \mathrm{H}_{\mathrm{f}}}$

Where:

$\mathrm{L}_{\mathrm{f}}=$ legibility distance in field experiment

$\mathrm{L}_{\mathrm{s}}=$ legibility distance in simulator experiment

$\mathrm{H}_{\mathrm{f}}=$ text height in field experiment

$\mathrm{H}_{\mathrm{s}}=$ text height in simulator experiment

$\mathbf{k}=$ magnification of text height

$a_{1}, a_{2}, b_{1}, b_{2}$ are constants in linear regression models

\subsection{Participants}

Thirty two subjects (with age ranging from 23 to 27) relatively balanced as concerns gender (17 male and 15 female). They were recruited from the student body of Beijing University of Technology. All subjects participated in the simulator experiment and 16 of them (8 male and 8 female) participated in the field experiment. All of them have driving license, no experience with the driving simulator and corrected visual acuity no less than 1.0. Participants were paid $¥ 40$ for their time.

\subsection{Field experiment}

Vehicle, GPS and laptop were used in field test. The experimental car was a Volkswagen Santana 2000 with a mileage of 90,000 km. DL-3V a type of GPS receiver produced by NovAtel a Norwegian company. NovAtel's DL-V3 is a general purpose high-performance receiver designed for base station and rover applications. It can provide real-time centimeter-level positions at an update rate of up to $20 \mathrm{~Hz}$. Laptop was used to setup time recorder software, which could record subjects' recognition time point.

The field study was conducted on the road that is located in the southeast part of Beijing University of Technology. It is a long straight with the length of $520 \mathrm{~m}$. A 285-meter section was chosen with the following characteristics: $12 \mathrm{~m}$ wide cross-section, no markings and signs on this road. As shown in Fig.2, guide sign was placed at point A at end of the road. Vehicle travels from point $\mathrm{D}$ to $\mathrm{A}$.

Weather condition was considered in this experiment, sunny day with well air quality. Experiment was conducted during 8:30-9:30, 10:00-11:30. In this period, it is working and school time, and there was no traffic flow and pedestrians. All above configurations could simplify factors. Sunny weather condition ensures the light intensity on signs was normal value.

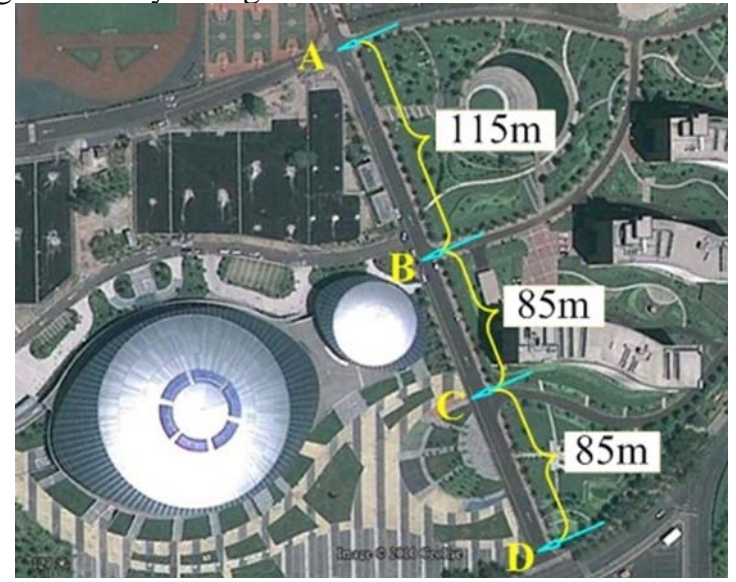

Fig.2. Field scenario

In field experiment, the text height of guide signs was $30 \mathrm{~cm}$, bold. According to GB5768-2009[10] regulations, guide sign letter height was determined by the design speed, when the speed was less than $40 \mathrm{~km} / \mathrm{h}$, the text height was $25 \mathrm{~cm}$ or $30 \mathrm{~cm}$. So text height of $30 \mathrm{~cm}$ in 
field experiment was chosen. Guide sign contains three different locations (Fig.3).

Experiments for guide sign recognition in field scenario were first executed. Participants sited in copilot position with a laptop. Prior to the experiment, experimenter informed participant location which participant needs to recognize. When a participant clearly recognized the place name, press the record key.

Every participant executed the experiment twice, the first experiment to make participant familiar with the scenario. Recognized time point in the second time was recorded as final data. Two of three locations were selected randomly. Participants had been informed the aim of experiment to test the legibility distance of guide sign.

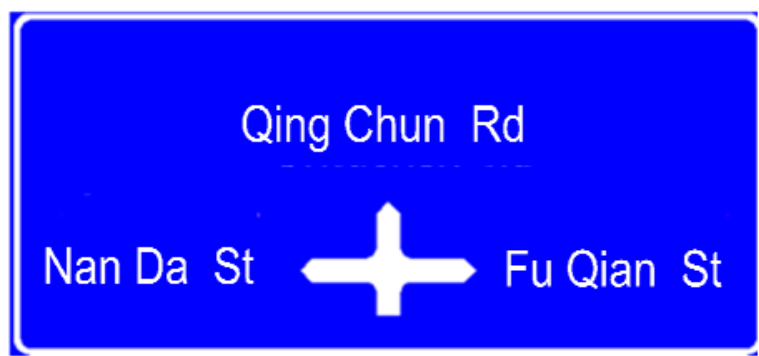

Fig.3. Guide sign

The data were collected by a Global Positioning System (GPS) device, installed on the experiment vehicle and connected to computer to store data. GPS was used to collect field data with position and velocity which presented recognized time point to traffic signs.

At the same time, the time point t1 of subjects' legibility point to traffic signs was recorded by time recorder. The clock of computer and GPS were synchronized to acquire the geographical coordinates of point $\mathrm{P}$ (la, lon) which was corresponding to the time point $\mathrm{t} 1$ of subjects' recognized point. The point $\mathrm{P}$ in the field road was found using GPS device based on the latitude and longitude coordinates. Subject's legibility distance could be measured easily.

\section{Driving simulator study}

A mid-level driving simulator located in the Transportation Research Center of Beijing University of Technology (BJUT-TRC), was used in this experiment. This driving simulator has the body of Toyota, and was surrounded by four screens. Three screens in the front of the vehicle subtended approximately 150' of visual angle. One screen located in the back of the vehicle. Each image was displayed on a screen at a resolution of 1024*768 pixels.

SimWorld simulator software was used to replicate field environment into simulator with high validity. It contains many applications including the ones that calculate the vehicle dynamics, the visual system, sound generation, control application, etc. As shown in Fig.4
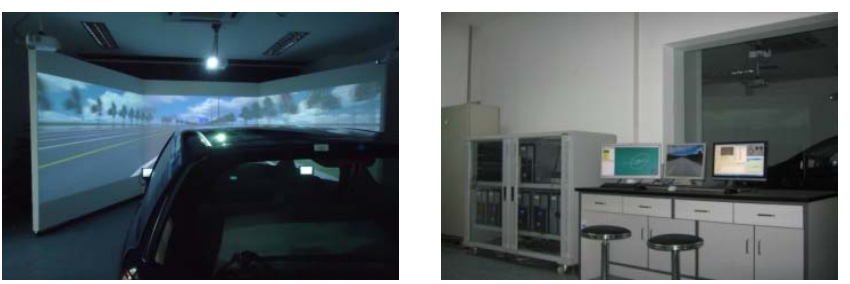

Fig.4. Driving simulator in BJUT-TRC

Virtual scenarios were built up in order to analyze the influence of magnifying power of text height on legibility distance. It consisted of five segments $(1 \mathrm{~km})$ which was similar with the field scenario. As shown in Fig.5, guide signs with different magnifying power were placed at the end of each segment. Guide signs used in simulator were the same as those in field test.

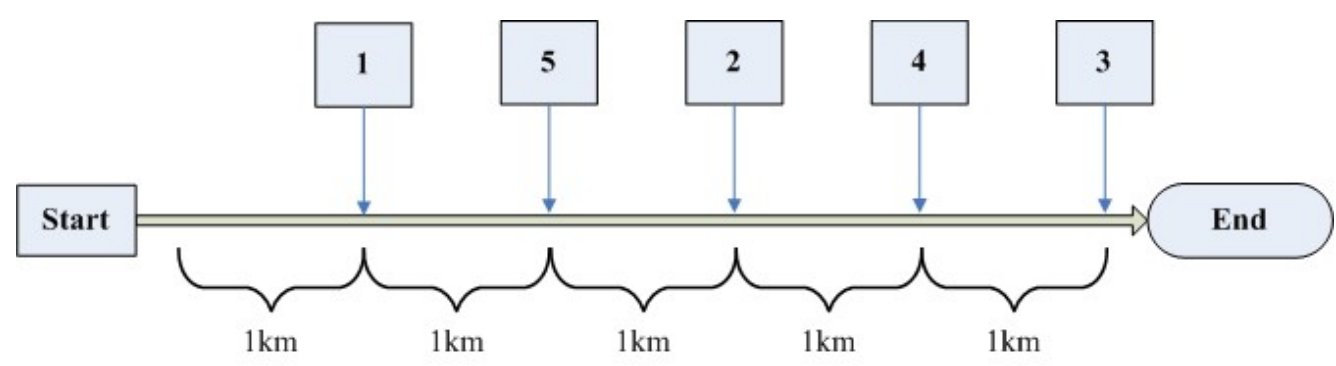

Fig.5. Layout of the five sections

Experiments for guide sign recognition in virtual scenario were conducted. During simulator experiment, vehicle was moving with specific speed. At the same time, participants needed to recognize guide sign 5 times per trip. Vehicle in the simulator was set to move at various speeds, 20, 30, 40 and $50 \mathrm{~km} / \mathrm{h}$. At the end of 
experiment, per participant recognized guide sign $5 * 4=20$ times in simulator.

The experimental method of how to record recognized time point was same to the one in field. Prior to the experiment, participants had 5 min to train in simulator to familiar with the virtual reality. And then formal test was implemented.

Parameters contained system time and coordinates of vehicle track were recorded during each test. Experimenter can calculate legibility distance to guide sign based on coordinates of corresponding to recognized time point and coordinates of guide sign.

\section{Results}

\subsection{Field experiment results}

This section demonstrates the vehicle speed affect legibility distance in field condition. Fig. 6 is a scatter plot presents the relationships between vehicle speeds with legibility distance (l-v graphs). Using SPSS statistical software analyzes field experiment data. Speed as independent variables, linear regression relational model is set up. Model formula is Eq.(5)

$\mathrm{Y}=171.86-1.884 * \mathrm{X} \quad(\mathrm{R} 2=0.615)$

Legibility distance can be calculated using Eq.5. The speed with the value of $30 \mathrm{~km} / \mathrm{h}$ and $40 \mathrm{~km} / \mathrm{h}$ correspond to legibility distance of $115.31 \mathrm{~m}$ and $96.48 \mathrm{~m}$.

Fig.6 shows that legibility distance and vehicle speed are inversely related, and that legibility distance increases with decreases in speed. The regression model has relatively low $r$ square value with noticeable scattering pattern of data, which may be caused by small sample size and confounding influence of various factors uncontrolled in the field scenario.

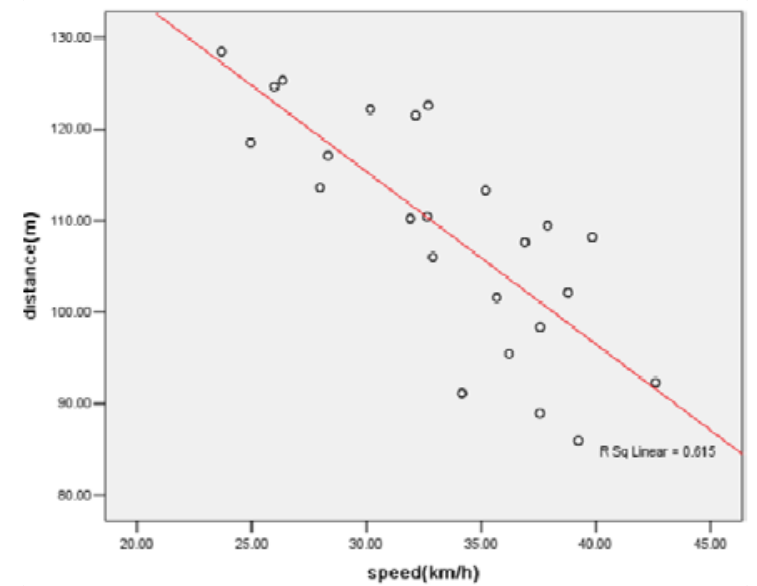

Fig.6. Speed and legibility distance relationship in field experiment

\subsection{Simulator experiment results}

In this section, vehicle speed and text height how to affect legibility distance to guide signs were studied. As shown in Fig.7- Fig.10, scatter plot represents the relationship between legibility distances with text height. Linear regression model were set up, text height as independent variable. Models in different speed conditions were listed in Table1. Table 2 lists legibility distances calculated from regression equations (Tab.1) for various speed and text height.

Vehicle speed and text height all affect legibility distance. Table 1 presents legibility distance and text height are positive related with high $\mathrm{r}$ square value. And legibility distance and speed are negative related which can be found from calculated data in Table 2 .

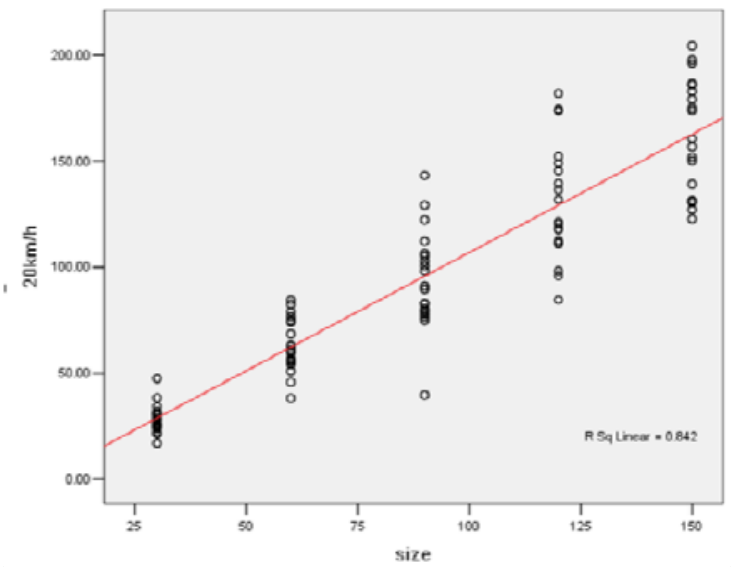

Fig.7. Text height and legibility distance relationship at speed $20 \mathrm{~km} / \mathrm{h}$

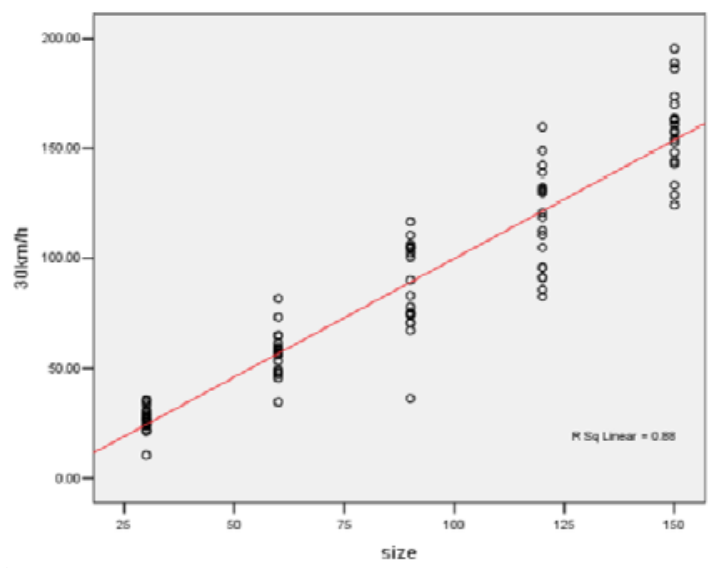

Fig.8. Text height and legibility distance relationship at speed $30 \mathrm{~km} / \mathrm{h}$ 


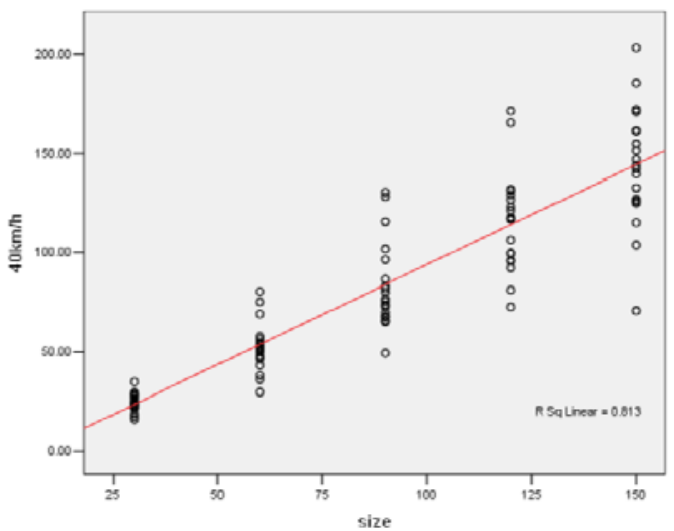

Fig.9. Text height and legibility distance relationship

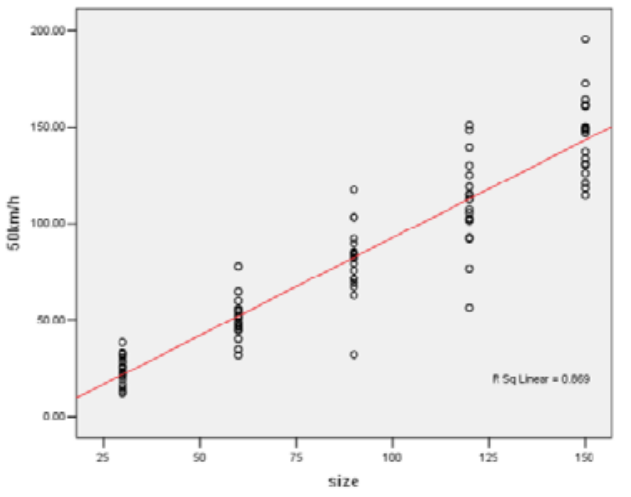

Fig.10. Text height and legibility distance relationship at speed $50 \mathrm{~km} / \mathrm{h}$

Table 1 Regression model in virtual experiment

\begin{tabular}{|c|c|c|c|c|c|c|}
\hline & & $\mathbf{V}$ & \multicolumn{2}{|c|}{ Equation } & \multicolumn{2}{|c|}{ R_square } \\
\hline \multicolumn{2}{|c|}{ linear } & $20 \mathrm{~km} / \mathrm{h}$ & \multicolumn{2}{|c|}{$Y=1.115 X-4.601$} & \multicolumn{2}{|c|}{0.842} \\
\hline \multicolumn{2}{|c|}{ linear } & $30 \mathrm{~km} / \mathrm{h}$ & \multicolumn{2}{|c|}{$Y=1.077 X-7.856$} & \multicolumn{2}{|c|}{0.88} \\
\hline \multicolumn{2}{|c|}{ linear } & $40 \mathrm{~km} / \mathrm{h}$ & \multicolumn{2}{|c|}{$Y=1.008 X-6.668$} & \multicolumn{2}{|c|}{0.812} \\
\hline \multicolumn{2}{|c|}{ linear } & $50 \mathrm{~km} / \mathrm{h}$ & \multicolumn{2}{|c|}{$Y=1.012 X-8.712$} & \multicolumn{2}{|c|}{0.869} \\
\hline \multicolumn{7}{|c|}{$\begin{array}{l}\text { Note: } \mathrm{Y} \text { is legibility distance }(\mathrm{m}) \text { and } \mathrm{X} \text { is vehicle speed }(\mathrm{km} / \mathrm{h}) . \\
\text { Table } 2 \text { Legibility distance in simulator }\end{array}$} \\
\hline \multirow{2}{*}{\multicolumn{2}{|c|}{$\begin{array}{c}\text { Legibility } \\
\text { distance(m) }\end{array}$}} & \multicolumn{5}{|c|}{ Text height(cm) } \\
\hline & & 150 & 120 & 90 & 60 & 30 \\
\hline \multirow{4}{*}{$\begin{array}{r}\text { Speed } \\
(\mathrm{km} / \mathrm{h})\end{array}$} & 20 & 162.34 & 130.41 & 94.55 & 63.41 & 28.45 \\
\hline & 30 & 158.31 & 117.07 & 86.65 & 57.14 & 26.59 \\
\hline & 40 & 144.01 & 115.69 & 83.72 & 52.32 & 24.50 \\
\hline & 50 & 140.00 & 110.72 & 80.83 & 50.11 & 24.31 \\
\hline
\end{tabular}

\subsection{Magnifying power}

Legibility distances were different generated by same text height in simulator and in field tests. In this section, magnifying power were studied which can be calculated with Eq.4. Table 3 lists the magnifying power in different speed conditions. Text height is $30 \mathrm{~cm}$ in field tests, while it is $124 \mathrm{~cm}, 114 \mathrm{~cm}, 102 \mathrm{~cm}$ in simulator corresponding to speed $20 \mathrm{~km} / \mathrm{h}, 30 \mathrm{~km} / \mathrm{h}, 40 \mathrm{~km} / \mathrm{h}$, and magnifying power $4.1,3.8,3.4$, which generate same legibility distances with that in field tests, respectively. Based on results in section 3.1 and 3.2, legibility distance in field test reduced faster than that in simulator, which led to magnifying power decreased with speed increasing. Table 3 Magnifying power calculation

\begin{tabular}{llll}
\hline Linear regression model (field) & \multicolumn{2}{l}{$\mathrm{S}=171.86$} & $-1.884 \mathrm{~V}$ \\
\hline Speed (km/h) & 20 & 30 & 40 \\
Legibility distance in field test (m) & 134.14 & 115.31 & 96.48 \\
Text height in virtual test (cm) & 124.31 & 114.25 & 102.32 \\
Magnifying power & 4.1 & 3.8 & 3.4 \\
\hline
\end{tabular}

\subsection{Comparative analysis}

The legibility distances deduced from calibrated text height in the driving simulator and the field ones were compared to find out whether the difference between them was acceptable. Fig.11 shows legibility distances deduced from text height $123 \mathrm{~cm}, 114 \mathrm{~cm}, 102 \mathrm{~cm}$, and obtained from field test. Same trends between them were existed, establishing the relative validities.

When speed was $30 \mathrm{~km} / \mathrm{h}$, the legibility distance corresponding to calibrated text height $114 \mathrm{~cm}$ was same to that in field. At same time, speeds increase $5 \mathrm{~km} / \mathrm{h}$, an increase of $4.6 \%$ error rate, and speeds decrease $5 \mathrm{~km} / \mathrm{h}$, an increase of $5.5 \%$ error rate. The error rates located in acceptable range with speed changed in the range of $10 \mathrm{~km} / \mathrm{h}$. So legibility distance was absolute validity in specific range of speed.

\section{Discussion}

In both the simulation field tests, when a participant recognized a sign, the data of recognition time was recorded. The distance between the participant and guide sign was then calculated. The legibility distance measured in this study was an integrated ability to recognize a guide sign. The legibility distance also included the effects of some variables that were not able to be measured. These variables included participant recognition delay, and physical reaction delay. As aging is a main factor contributing to these delay types, only young healthy people were recruited for the experiment 
in an effort to reduce and control these variable effects. In addition, air condition was considered in experiment to exclude its influence on legibility distance. Limitations about text height of guide sign and vehicle speed range were existed in this study.

According to regulation GB5768-2009[11], parameters of guide sign dependent on speed and road

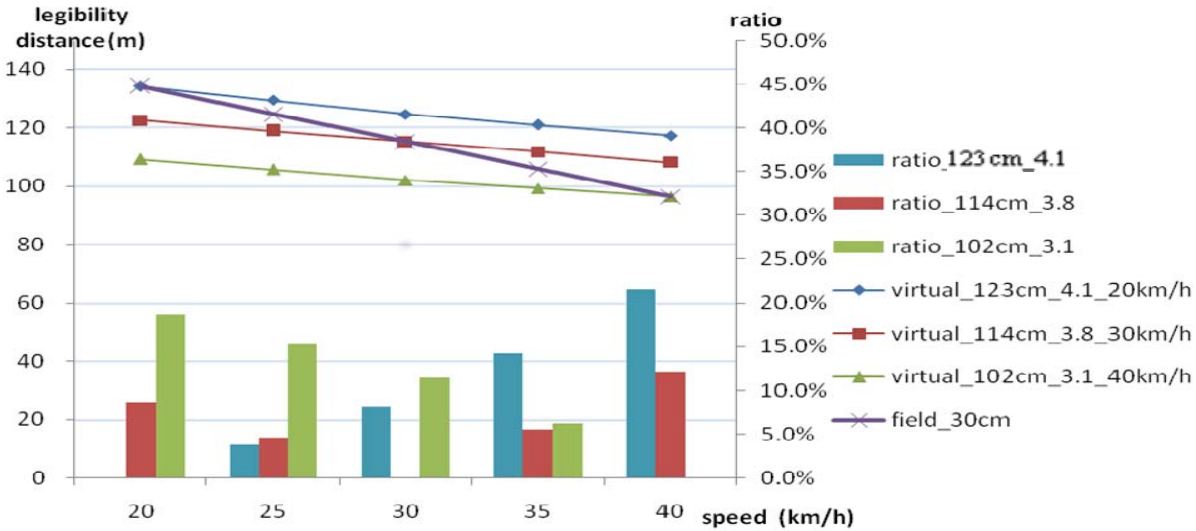

Fig.11. Comparative analysis legibility distance in field and virtual scenarios after calibration
Legibility distances in dynamic conditions were larger than previous study ${ }^{[12]}$. This study was carried out under ideal conditions. Subjects sited at the co-pilot, which allows people focus on recognizing guide signs, rather than distraction mission, driving and other tasks. So that legibility distances measured from experiment were longer than that recorded by drivers in actual situation. However, legibility distances in experiment which exclude many influence factors were always meaningful. It can be used as an absolute reference value. similar with previous study (Ting, 2008). Ting (2008) indicated the time needed to recognize a traffic sign does not change too much with driving speeds, a faster driving speed gives a further driving distance in a given time period and, thus, a shorter legibility distance is induced. In addition, the display system resolution in simulator has an important role in determining legibility distance. Hendrix and Barfield indicated that a high resolution enhances the sensation of presence and thus people recognize traffic sign at a long legibility distance $^{[13]}$. An improvement of the fidelity of visual simulation system, by implementing a new projector with high resolution to effectively simulate traffic sign,
Speed and legibility distance were negatively related grade. Speed range $20-50 \mathrm{~km} / \mathrm{h}$ corresponds to $30 \mathrm{~cm}$ text height of guide sign. Although the experimental design parameters have some limitations, values of parameters in the study were existed in realistic road environment. could help to increase the legibility distance in simulator as well as reduce the magnification of guide sign size $^{[14,15]}$. As legibility distances were sensitive to speed and resolution, calibration for text height on guide sign was necessary to make guide signs absolute validity in simulator.

\section{Conclusions}

The objective of this study is to provide guidelines for testing signage validity using driving simulator. Simulator calibration procedure for guide sign was set up. One scenario in field and five scenarios with different magnifying power in simulator were set up. Legibility distance as measure of performance was used to evaluate the validity of driving simulator. Statistical regression and comparison were performed to analyze data measured in simulator and field. Based on the analysis results, the major findings of this study are summarized as following:

- In field test, holding text height constant, speed and legibility distance were negatively correlated, reflected by a relatively smaller r-square value. In simulator test, text height and legibility distance were positively related, and the relation between speed and legibility distance was same with those in field test. 
For a specified speed value, legibility distances in simulator after magnified text height of guide sign equal to those measure in field. When speed fluctuated with $5 \mathrm{~km} / \mathrm{h}$, the variation of legibility distance in simulator was less than 6\%. The research findings of this study support the concept that the driving simulator experiment in virtual reality after calibration can be utilized as a valid tool to simulate guide sign.

Further studies with larger sample size are required in order to study the relationship between speed and legibility distance precisely with sufficient statistical value of $\mathrm{R}$ square and to increase the range of speed, $40 \mathrm{~km} / \mathrm{h}-90 \mathrm{~km} / \mathrm{h}$, in order to fully verify the formulated hypotheses and find relationships between speed and legibility distance in simulator and on real road.

\section{References}

1. Auberlet J, Pacaux M, Anceaux F, et al. The impact of perceptual treatments on lateral control: A study using fixed-base and motion-base driving simulators[J]. Accident Analysis \& Prevention. 2010, 42(1): 166-173

2. Dutta A, Fisher D L, Noyce D A. Use of a driving simulator to evaluate and optimize factors affecting understandability of variable message signs[J]. Transportation Research Part F: Traffic Psychology and Behaviour. 2004, 7(4-5): 209-227.

3. Boyle L N, Lee J D. Using driving simulators to assess driving safety[J]. Accident Analysis \& Prevention. 2010, 42(3): 785-787.

4. Antonson H, Madh S, Wiklund $\mathrm{M}$, et al. Effect of surrounding landscape on driving behaviour: A driving simulator study[J]. Journal of Environmental Psychology. 2009, 29(4): 493-502.

5. Blaauw G J. Driving experience and task demands in simulator and instrumented car: A validation study[J].
Human Factors: The Journal of the Human Factors and Ergonomics Society. 1982, 24(4): 473-486.

6. Kaptein N A, Theeuwes J, Van Der Horst R. Driving simulator validity: Some considerations[J]. Transportation Research Record: Journal of the Transportation Research Board. 1996, 1550(-1): 30-36.

7. Klee $\mathrm{H}$, Bauer $\mathrm{C}$, Radwan E, et al. Preliminary validation of driving simulator based on forward speed[J]. Transportation Research Record: Journal of the Transportation Research Board. 1999, 1689(-1): 33-39.

8. Bella F. Validation of a driving simulator for work zone design[J]. Transportation Research Record: Journal of the Transportation Research Board. 2005, 1937(-1): 136-144.

9. Yan X, Abdel-Aty M, Radwan E, et al. Validating a driving simulator using surrogate safety measures[J]. Accident Analysis \& Prevention. 2008, 40(1): 274-288.

10. Ting $\mathrm{P} \mathrm{H}$, Hwang $\mathrm{J}$ R, Fung $\mathrm{C} P$, et al. Rectification of legibility distance in a driving simulator[J]. Applied Ergonomics. 2008, 39(3): 379-384.

11. National Standard Specification GB5768-2009, Road traffic signs and markings, SAC, Beijing, China, July 2009.

12. Ullman B R, Ullman G L, Dudek C L, et al. Legibility Distances of Smaller Letters in Changeable Message Signs with Light-Emitting Diodes[J]. Transportation Research Record: Journal of the Transportation Research Board. 2005, 1918(-1): 56-62.

13. Hendrix C, Barfield W. Presence in virtual environments as a function of visual and auditory cues[C]. Published by the IEEE Computer Society, 1995.

14. Wuhong Wang, Xiaobei Jiang, Shuangcheng Xia, Qi Cao, Incident tree model and incident tree analysis method for quantified risk assessment: an in-depth accident study in traffic operation, Safety Science, 2010 48(10),1248-1262.

15. Wuhong Wang,Wei Zhang,Hongwei Guo,Heiner Bubb,Katsushi Ikeuchi, A safety-based behavioural approaching model with various driving characteristics, Transportation Research Part C-Emerging Technologies, doi:10.1016/j.trc.2011.02.002. 